\title{
Territorial prior residence effect versus intruder size advantage in convict cichlids (Cichlasoma nigrofasciatum Günther)
}

\author{
MICHAEL H. FIGLER, BERNARD E. WAZLAVEK, and LIN M. CHAVES \\ Towson State University, Towson, Maryland
}

\begin{abstract}
The consequences of an intruder size advantage on the territorial prior residence effect were investigated using resident-intruder pairs in which the intruder was $10 \%-20 \%, 25 \%-35 \%$, or 40\%-50\% larger than the resident fish. Regardless of the magnitude of the size advantage, intruders established dominance in every pair in which any aggression occurred and delivered significantly more attacks (bites) than did residents. Apparently, an intruder size advantage (fighting ability asymmetry) can overwhelm the territorial prior residence effect (uncorrelated asymmetry) relatively easily.
\end{abstract}

Recent studies using two highly territorial species of the family Cichlidae-convict cichlids (Cichlasoma nigrofasciatum) and jewel fish (Hemichromis bimaculatus)-have shown that when a territorial resident and conspecific intruder are matched on all characteristics except the prior residence asymmetry, the resident reliably dominates (Figler \& Einhorn, 1983; Figler \& Evensen, 1979; Figler, Klein, \& Peeke, 1976; Figler \& Peeke, 1978).

Variables such as time out of one's territory, extraterritorial experiences, and length of territorial residence (Figler \& Einhorn, 1983), as well as intra- and extraterritorial visual cues (Figler, Dyer, Streckfus, \& Nardini, 1975; Figler, Wazlavek, Spencer, \& Gussio, 1985), are important in this prior residence effect. However, an attempted disruption of the prior residence effect by manipulating these variables has simply reduced the dominance outcomes to a chance level (symmetric contest) (Maynard Smith \& Parker, 1976) between resident and intruder; in no experiment has an experimental manipulation resulted in a significant intruder dominance advantage over residents.

In all of these studies, resident-intruder pairs have been matched for body size (no difference larger or smaller than $5 \%$ of resident's body length). In general, past studies using a variety of fish species have reported that relative size provides an important asymmetric cue in settling intraspecific aggressive encounters (Barlow, Rogers, \& Fraley, 1986; Enquist, Ljundberg, \& Zandor, 1987). The present preliminary study specifically investigated the ef-

The authors would like to thank Betty A. Walko for her help in collecting data. The second author is now at the Department of Psychology, Utah State University, Logan, UT 84322. The third author is now at the Department of Psychology and Institute of Animal Behavior, University of Maryland, College Park, MD 20742. Requests for reprints should be sent to Michael H. Figler, Department of Psychology, Towson State University, Towson, MD 21204. fects of an intruder size advantage on the territorial prior residence advantage. In other words, competing asymmetries (prior residence advantage vs. intruder size advantage) of varying degrees were created, with an intruder being from $10 \%-50 \%$ larger than the territorial resident, and the outcomes of direct territorial intrusions evaluated.

\section{METHOD}

\section{Subjects and Apparatus}

Thirty adult convict cichilds, $5-8 \mathrm{~cm}$ in length and from a commercial supplier, served as subjects. Subject sex was not controlled, because both males and females establish territories and both exhibit territorial aggression against conspecific intruders irrespective of sex (Cole, Figler, Parente, \& Peeke, 1980). The housing, feeding, and procedural aspects of the present study were used previously (e.g., Figler et al., 1985), and are only summarized here. After being held in community tanks (65 liter, $78 \times 32 \times 31 \mathrm{~cm}$ ) for 2 weeks, subjects were transferred to individual glass test aquaria (21 liter, $41 \times 21 \times 26 \mathrm{~cm})$ containing a coarse gravel substrate and one of two types of territorial markers (terracotta pot or clump of plastic plants).

\section{Procedure}

Prior to being placed in the individual territorial aquaria, fish were randomly assigned to three independent treatment conditions, with five pairs in each group: (1) the intruder having a body length 10\%-20\% greater than that of the resident, (2) the intruder having a body length $25 \%-35 \%$ greater than the resident, and (3) the intruder having a body length $40 \%-50 \%$ greater than the resident. For all groups body length was defined as the length of the fish from the tip of the snout to the beginning of the caudal fin. The fish were given a 3-day residence period prior to testing. One pair member always came from a pot condition, and the other came from a plant condition. However, the territorial marker in a subject's individual tank was randomly determined (Figler \& Einhorn, 1983).

The direct encounters consisted of netting both resident and intruder, bisecting the resident's tank into two equal-sized compartments with an opaque Plexiglas partition, and returning the resident to the side with the territorial marker and the intruder to the other compartment. After a 15-min adaptation period, the partition was removed. The subject that bit first (the subject that first butted its opponent with its mouth open or closed) and the frequency of bites by both resident and intruder were recorded. The victor of the bout was also recorded.

A subject was designated as being the victor (i.e., establishing dominance) after demonstrating six consecutive unanswered dominance 
behaviors, such as displaying at, biting, butting, or chasing its opponent, with the fish being attacked making an immediate escape movement or assuming a submissive posture (see Figler et al., 1976, for a more detailed description). The bout was terminated and the data not included in the analysis if no agonistic behavior occurred within $15 \mathrm{~min}$ after the initiation of the dominance encounter.

\section{RESULTS}

Due to the small sample sizes and lack of appreciable differences between treatment conditions, the data were pooled for statistical analysis. There was aggression shown in 11 of 15 pairs (4 pairs in the $10 \%-20 \%$ group, 3 pairs in the $25 \%-35 \%$ group, and 4 pairs in the $40 \%-50 \%$ group), with the intruder dominating in all 11 contests. A two-tailed Fisher exact probability test showed this intruder dominance advantage to be highly significant $(p<.01)$. Also, intruders showed a significantly higher number of bites $(M=22.91, S D=16.31)$ than did residents $(M=4.73, S D=5.53)$ in all 11 paired encounters (sign test, $p<.01$, two-tailed).

There was no significant difference in the proportions of residents versus intruders attacking (biting) first (Fisher exact probability test, $p>.05$, two-tailed). Finally, biting first did not reliably predict eventual dominance (Fisher exact probability test, $p>.05$, two-tailed).

\section{DISCUSSION}

These results suggest that an intruder size advantage of as little as $10 \%-20 \%$ in body length can result in an intruder dominance advantage. Although past studies with $C$. nigrofasciatum and $H$. bimaculatus have manipulated many aspects of a resident's experience and environment, the prior residence effect has been shown only to be subject to a return to equity (i.e., resident and intruder have an equal chance of dominating). No significant intruder advantage has occurred in any of these studies. In the species used in the present study, an intruder size advantage (fighting ability asymmetry) apparently is an important enough cue to overcome a prior residence advantage (uncorrelated asymmetry) (Maynard Smith \& Parker, 1976), at least within the parameters used.

A field study using female funnel web spiders (Riechert, 1978) also found that if the size (weight) difference beween resident and intruder was less than $10 \%$, the resident was dominant. However, if the intruder size advantage was greater than that, the intruder dominated the resident. In general, territorial ownership is respected, all other possible asymmetries being equal, but an intruder size advantage can overwhelm the advantage of territorial prior residence (Hammerstein, 1981).

\section{REFERENCES}

Barlow, G. W., Rogers, W., \& Fraley, N. (1986). Do Midas cichlids win through prowess or daring? It depends. Behavioral Ecology \& Sociobiology, 19, 1-8.

Cole, H. W., Figler, M. H., Parente, F. J., \& Peeke, H. V. S. (1980). The relationship between sex and aggression in convict cichilds (Cichlasoma nigrofasciatum Günther). Behaviour, 75, 1-21.

ENQUist, M., LJUNDBERG, T., \& ZANDOR, A. (1987). Visual assessment of fighting ability in the cichild fish Nannacara anomala. Animal Behaviour, 35, 1262-1264.

Figler, M. H., Dyer, R. S., Streckfus, C. F., \& NARdini, K. M. (1975). The establishment of dominance relationships in jewel fish, Hemichromis bimaculatus (Gill), as related to prior exposure to and configuration of visual cues. Behavioral Biology, 14, 241-245.

Figler, M. H., \& EINHORN, D. M. (1983). The territorial prior residence effect in convict cichlids (Cichlasoma nigrofasciatum Günther): Temporal aspects of establishment and retention, and proximate mechanisms. Behaviour, 85, 157-183.

Figler, M. H., \& EVENSEN, J. (1979). Experimentally produced prior residence effect in male convict cichlids: The role of initial proximity to territorial markers. Bulletin of the Psychonomic Society, 13, 130-132.

Figler, M. H., Klein, R. M., \& Peeke, H. V. S. (1976). The establishment and reversibility of dominance relationships in jewel fish, Hemichromis bimaculatus Gill (Pisces, Cichlidae): Effects of prior exposure and prior residence situations. Behaviour, 58, 254-271.

Figler, M. H., \& Peeke, H. V. S. (1978). Alcohol and the prior residence effect in male convict cichlids (Cichlasoma nigrofasciatum). Aggressive Behavior, 4, 125-132.

Figler, M. H., Wazlavek, B. E., Spencer, F. P., \& Gussio, R. P. (1985). The influence of chemical cues on the territorial prior residence effect in convict cichlids (Cichlasoma nigrofasciatum Günther). Aggressive Behavior, 11, 207-216.

Hammerstein, P. (1981). The role of asymmetries in animal contests. Animal Behaviour, 29, 193-205.

Maynard Smith, J., \& Parker, G. A. (1976). The logic of asymmetric contests. Animal Behaviour, 24, 159-175.

RIECHERT, S. E. (1978). Games spiders play: Behavioral variability in territorial disputes. Behavioral Ecology \& Sociobiology, 3, 135-162.

(Manuscript received for publication January 28, 1988.) 